\title{
Pendampingan Akselerasi Jurnal Kesehatan Stikes Cirebon Menuju Jurnal Berbasis OJS Dan Terakreditasi
}

\author{
Syaeful Bakhri ${ }^{1}$, Lilis Banowati ${ }^{2 *}$ \\ ${ }^{1}$ IAIN Syekh Nurjati Cirebon \\ ${ }^{2}$ STIKes Cirebon \\ 1e-mail:sultan01aulia@yahoo.com \\ 2e-mail: lilisbanowati508@yahoo.com \\ *Corresponding Author
}

\begin{abstract}
ABSTRAK
Program kegiatan pengabdian ini bertujuan untuk melakukan pendampingan kepada tim pengelola jurnal kesehatan dan para dosen di lingkungan STIKes Cirebon agar dapat meningkatkan akselerasi jurnal kesehatan STIKes Cirebon menuju jurnal berbasis Open Journal System dan terakreditasi melalui metode penyampaian secara ceramah, diskusi dan demonstrasi pemanfaatan Open Journal System. Berdasarkan program kegiatan pengabdian ini, masih ditemukan beberapa diantara tim pengelola yang merasa berat memahami prosedur dan sistem pengelolaan e-Journal sehingga dapat terakreditasi. Sejalan dengan hal tersebut, maka kegiatan pengembangan kapasitas Dosen dan Tim pengelola STIKes Cirebon dalam hal Publikasi karya ilmiah masih perlu ditingkatkan. Hal ini tidak lain adalah untuk mengembangkan kualitas dan kuantitas hasil publikasi pada Jurnal Kesehatan STIKes Cirebon.
\end{abstract}

Kata Kunci: Pendampingan, Jurnal Kesehatan, OJS, Akreditasi

\begin{abstract}
This service activity program aims to provide assistance to the Health Journal Management Team and Lecturers in the Cirebon STIKes Environment to increase the acceleration of the Cirebon, STIKes health journal towards the Open Journal System based journal and be accredited through the method of delivering lectures, discussions, and demonstrations of the use of the Open Journal System. Based on this program of service activities, there are still some among the Management Team who find it difficult to understand the procedures and management systems of the e-Journal so that they can be accredited. In line with this, the capacity building activities of the Lecturers and Management Team of STIKes Cirebon in terms of publication of scientific works still need to be improved. This is nothing but to develop the quality and quantity of publications in the STIKes Cirebon Health Journal.
\end{abstract}

Keywords: Assistance, Health Journal, OJS, Accreditation 


\section{PENDAHULUAN}

Penggunaan teknologi informasi pada era globalisasi saat ini,telah menjadi pilihan utama setiap organisasi maupun perusahaan dalam meningkatkan daya saing dan keunggulan di tengah persaingan yang semakin kompetitif. Pentingnya teknologi yang dibantu dengan sistem informasi pada setiap lini kehidupan sangat dapat dipahami sebagai faktor yang menyebabkan terjadinya perubahan pertumbuhan pada sistem sosial, pendidikan dan ekonomi (Aswati, Mulyani, Siagian, \& Syah, 2015). Misalnya saja penggunaan internet dan komputer dalam dunia pekerjaan yang dapat menghasilkan output secara cepat, akurat dan relevan. (Dewanto, 2017) juga menyebutkan pentingnya internet sebagai penyalur komunikasi yang efektif karena dapat menyalurkan informasi secara tepat sasaran. Maka dapat dipahami bahwasanya pemanfaatan teknologi informasi khususnya teknologi komputer yang berfungsi sebagaisangat signifikan dalam meningkatkan tingkat efisiensi dan efektifitas kerja sehingga dapat menghemat waktu, tenaga dan fikiran.

Perkembangan perubahan dunia melalui teknologi informasinya tersebut telah mendorong institusi perguruan tinnggi pada persaingan yang semakin ketat. Oleh sebab itu, tidak heran jika Pemerintah melalui Kemenrisetdikti sangat menekankan pada penguatan resources dengan kesiapan terhadap perubahan persaingan global (Darmalaksana, 2017). Indikator kualitas Perguruan Tinggi dapat ditandai oleh mutu penelitian seperti jurnal ilmiah yang sesuai standar nasional. Jurnal ilmiah merupakan majalah yang memuat artikel dalam bidang kajian ilmu tertentu yang berbentuk terbitan berkala dan berfungsi sebagai peregistrasian kegiatan para cendekiawan untuk kemudian dapat menjadi sarana disemainasi karya ilimiah kepada khalayak luas.

Program akreditasi terbitan jurnal berkala ilmiah bertujuan untuk meningkatkan kualitas dan kuantitas terbitan berkala ilimiah agar dapat berdaya saing dengan jurnal Internasional (Nashihuddin \& Aulianto, 2017). Penilaian akreditasi terbitan berkala ilmiah nasional dilaksanakan oleh Lembaga Ilmu Pengetahuan Indonesia (LIPI) dan Direktorat Jenderal Pendidikan Tinggi (DIKTI) yang dalam pedoman akreditasinya ditetapkan lebih menekankan kepada peniliain penerbitan jurnal ilmiah secara elektronik (online) untuk menjamin akuntabilitas, kualitas dan reputasi terbutan berkala ilmiah.Oleh sebab itu, dimulai pada tanggal 6 April 2016 Pemerintah mengeluarkan Surat Edaran Dirjen Risbang-DIKTI No. 93/E/SE/XII/2015 tentang Akreditasi Jurnal Ilmiah Secara Eletronik dan menetapkan bahwa akreditasi jurnal ilmiah nasional hanya diperuntukkan bagi jurnal elektronik yang dikelola melalui sistem aplikasi berbasis Open Journal System (OJS) (Nashihuddin \& Aulianto, 2017).

Jurnal elektronik merupakan sebuah cara yang memungkinkan terjadinya proses komunikasi yang lebih cepat dibanding dengan terbitan berkala ilmiah versi cetak seperti buku 
(Siregar, 2008). Terbitan yang semula tercetak dengan proses yang cukup lama dan berbiaya, kini menjadi lebih cepat dan ekonomis melalui bantuan sistem aplikasi yang memanfaatkan teknologi informasi. Open Journal System (OJS) adalah suatu sarana pengelolaan jurnal eletronik yang berbasis web yang memudahkan dalam proses penerimaan naskah, distribusi naskah, pemeriksanaan dan penyuntingan naskah hingga proses penerbitan jurnal (Astuti \& Isharijadi, 2019). Selain dapat terakreditasi secara nasional, melalui Open Journal System (OJS), suatu perguuruan tinggi juga dapat memperkenalkan dan mempublikasikan hasil karya civitas akademikanya secara global (Yunus, Abadi, Bhuana, \& Djalal, 2018).

Jurnal Kesehatan STIKes (Sekolah Tinggi Ilmu Kesehatan) Cirebon merupakan jurnal ilmiah tentang kesehatan yang dikelola oleh Lembaga Pengembangan, Penelitian, dan Pengabdian Masyarakat STIKes Cirebon sebagi sarana publikasi ilmiah tentang perkembangan ilmu pengetahuan dan teknologi di sektor kesehatan meliputi bidang kesehatan masyarakat, keperawatan, kebidanan, fisioterapi, radiodiagnotik, farmasi dan analisis kesehatan. Sejak tahun 2015, Jurnal Kesehatan telah memiliki p-ISSN (2088-0278) sebagai tanda pengenal untuk setiap terbitan berkala secara global. Namun dalam perkembangannya, hingga tahun 2019 Jurnal Kesehatan STIKes Cirebon belum mampu mengembangkan Jurnal tersebut menjadi sebuah terbitan berkala ilmiah yang menggunakan sistem Open Journal System (OJS).

Terbatasnya pengetahuan Tim pegelola jurnal Kesehatan STIKes Cirebon terkait pengelolaan dan pengembangan Jurnal merupakan salah satu kendala yang dihadapi saat ini. Berangkat dari hal tersebut, maka kegiatan langkah improvement perlu dilakukan agar media yang dimiliki dapat menyajikan informasi dapat lebih berkualitas (Dewanto, 2017). Penerapan sistem aplikasi berbasis Open Journal System (OJS) dalam penerbitan jurnal pada suatu Perguruan tinggi akan memantu meningkatkan efisiensi dan efektivitas proses pengelolaan dan penerbitan terbitan berkala imiah pada Jurnal Kesehatan STIKes Cirebon. Kegiatan berupa pendampingan pengelolaan jurnal dari jurnal cetak menjadi jurnal elektronik/online (e-Journal) melalui sistem aplikasi berbasis OJS dinilai sebagai langkah strategis untuk meningkatkan akselerasi Jurnal Kesehatan STIKes Cirebon menuju jurnal berbasis Open Journal System (OJS) dan terakreditasi.

\section{BAHAN DAN METODE}

Publikasi ilmiah adalah sebuah proses komunikasi dalam lingkungan akademik untuk menyebarluaskan hasil penelitiannya sebagai bentuk kontribusi pengembangan ilmu pengetahuan (Astuti \& Isharijadi, 2019). Tujuannya yaitu untuk 1). Meregistrasi kegiatan kecendekiaan, 2). Melakukan sertifikasi atas hasil kegiatan yang telah memenuhi persyaratan ilmiah, 3). Menyebarluaskan hasil kegiatan kepada masyarakat luas, serta 4). Mengarsipkan semua 
temuan hasil kegiatan kecendekiaan pada bidang keilmuan dan pakar yang telah dimuatnya. Sementara itu, akreditasi terbitan berkala ilmiah adalah pengakuan secara resmi atas jaminan mutu kualitas ilmiah melalui serangkaian proses kewajaran penyaringan naskah, kelayakan pengelolaan dan ketepatan waktu penerbitan suatu terbitan berkala ilmiah (Nashihuddin \& Aulianto, 2017).

Adapun jurnal nasional terakreditasi adalah majalah ilmiah yang memenuhi kriteria sebagai jurnal nasional berdasarkan peraturan Dirjen Dikti atau Kepala LIPI tentang terbitan berkala ilmiah dan mendapat status terakreditasi dari Direktorat Jenderal Pendidikan Tinggi atau kepala LIPI dengan masa berlaku hasil akreditasi yang sesuai(Lukman, 2016). Syarat yang perlu dipenuhi agar suatu publikasi berkala ilmiah dapat terakreditasi menurut Sadjuda dalam (Junandi, 2018) adalah;

1. Publikasi berkala ilmiah berisi karya ilmiah ditulis sesuai dengan kaidah ilmiah dan etika keilmuan

2. Publikasi berkala ilmiah telah memiliki ISSN

3. Publikasi berkala ilmiah memiliki terbitan versi elektronik (e-Journal)

4. Publikasi berkala ilmiah memiliki tujuan untuk menghimpun dan menginformasikan hasil penelitian ilmiah dan atau konsep ilmiah pada disiplin ilmu tertentu

5. Publikasi berkala ilmiah ditujukan kepada para peneliti yang memiliki relevansi disiplin keilmuan

6. Publikasi berkala ilmiah diterbitkan oleh Organisasi Keilmuan/ Badan Ilmiah/ Organisasi Profesi/ Perguruan Tinggi berikut unit-unitnya

7. Publikasi berkala ilmiah Berbahasa Indonesia dan atau Berbahasa Inggris

8. Karya ilmiah berasal dari minimal dua institusi yang berbeda

9. Memiliki dewan redaksi/ editor yang berasal dari para ahli pada bidang disiplin keilmuan dan berasal dari minimal dua institusi yang berbeda.

Jenis pemberdayaan pada kegiatan ini adalah melalui pendampingan pengelolaan Jurnal Kesehatan STIKes Cirebon dari Jurnal cetak menjadi Jurnal elektronik/online. Kegiatan pendampingan dilaksanakan pada bulan Januari hingga Maret 2020. Berikut merupakan metode penerapan program kegiatan pengabdian ini: 


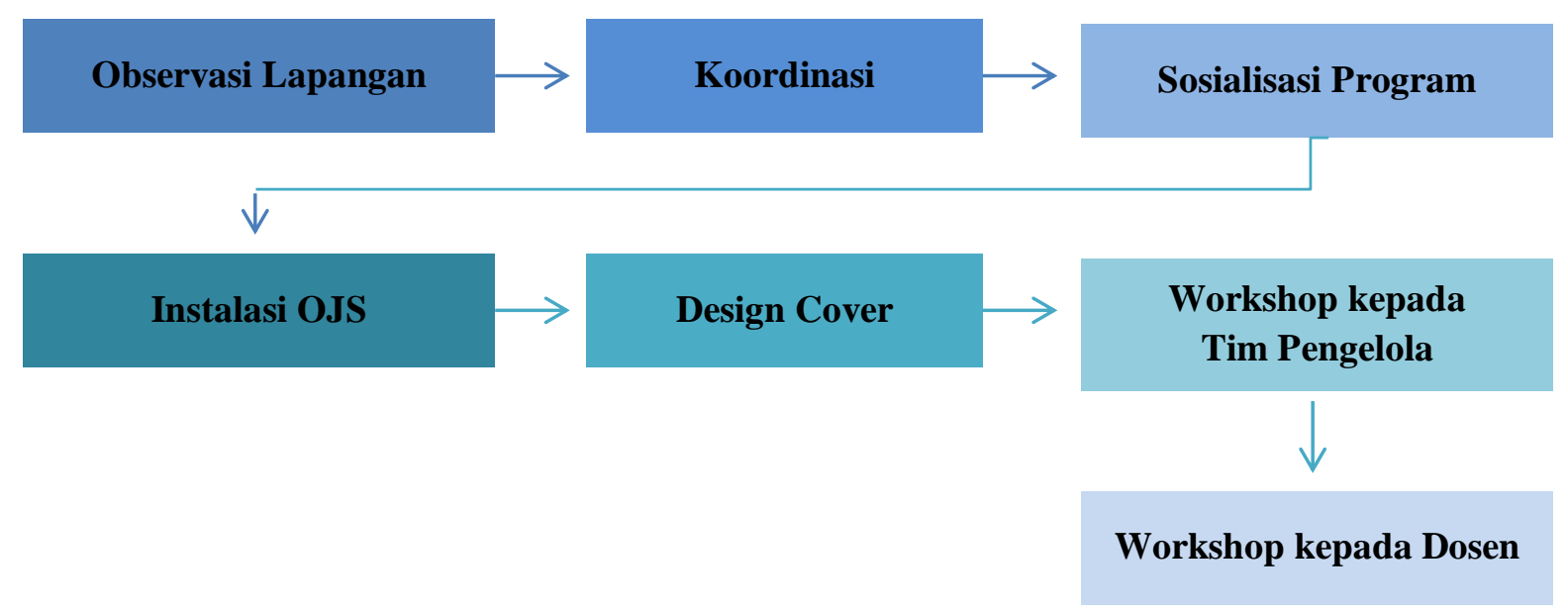

\section{Gambar. 1 Metode Penerapan Program Kegiatan}

Kegiatan pendampingan pengelolaan Jurnal Kesehatan dilakukan melalui metode penyampaian secara ceramah, diskusi dan demonstrasi secara langsung bersama tim pengelola Jurnal Kesehatan STIKes Cirebon sekaligus para Dosen di Lingkungan STIKes Cirebon. Para peserta kegiatan diwajibkan untuk membawa laptop dengan koneksi jaringan yang memadai agar kegiatan pendampingan dapat berlangsung secara efektif. Target output dengan dilaksanakannya kegiatan pendampingan ini adalah agar menghasilkan akselerasi Jurnal Kesehatan STIKes Cirebon sehingga siap menuju Jurnal berbasis OJS dan terakreditasi.

\section{HASIL DAN PEMBAHASAN}

Kegiatan pendampingan dan pemberdayaan telah dilaksanakan pada bulan Januari hingga Mei 2020. Kegiatan tersebut meliputi beberapa tahapan kegiatan, dimulai dengan observasi lapangan untuk mengetahui permasalahan ataupun kendala yang ada dilapangan. Setelah diketahui permasalahan, Tim pelaksana program pengabdian melakukan koordinasi bersama untuk kemudian dikoordinasikan kembali dengan Tim pengelola Jurnal Kesehatan yaitu Lembaga Pengembangan, Penelitian, dan Pengabdian Masyarakat STIKes Cirebon. Hal-hal yang dibahas adalah tentang rencana program pemberdayaan, meliputi waktu dan tempatpelaksanaan program pemberdayaan, bagaimana proses pendampingan yang akan dilakukan dan diberikan kepada Tim pengelola Jurnal Kesehatan dan para Dosen di Lingkungan STIKes Cirebon, serta persiapan apa saja yang diperlukan untuk menyelenggarakan kegiatan pendampingan tersebut.

Setelah pelaksanaan koordinasi tersebut, Tim pelaksana program pengabdian melakukan sosialisasi rencana program-program kegiatan yang telah dirumuskan sebelumnya. Kemudian tim pelaksana program pengabdian kemudian mendampingi tim pengelola Jurnal Kesehatan untuk 
menyiapkan instalasi OJS pada Jurnal Kesehatan STIKes Cirebon termasuk design cover yang akan dimuat pada laman publikasi ilmiah berupa e-Journal berbasis OJS kedepan.

Program kegiatan pengabdian dilanjutkan dengan diselenggarakannya workshop kepada Tim pengelola Jurnal Kesehatan STIKes Cirebon dan para Dosen di lingkungan STIKes Cirebon. Kegiatan Workshop dibagi menjadi dua sesi, yaitu penyampaian teori secara umum tentang ejournal terutama OJS dalam pengelolaan jurnal dan sesi kedua berupa demontrasi pemanfaatan OJS. Dalam sesi awal Workshop, pendamping sebagai narasumber menyampaikan pengetahuan dasar terkait fungsi dan manfaat e-Journal. Pada materi ini, disampaikan kelebihan dan manfaat dari penggunaan e-Journal, seperti mendapatkan kemudahan akses publikasi ilmiah, kecepatan mendapat referensi, membantu mempercepat proses penyebarluasan jurnal ilimiah dengan ekonomis juga mampu meningkatkan rangking perguruan tinggi baik secara nasional maupun global.

Dalam sesi ini, narasumber juga menjelaskan tentang ketetapan akreditasi terbitan berkala ilmiah termasuk didalamnya mengenai persyaratan dalam pengajuan akreditasi jurnal ilmiah yang mengacu pada Peraturan Dirjen DIKTI No.1 tahun 2014 tentang Pedoman Akreditasi Terbitan Berkala Ilmiahsebagai hasil kesepakatan antara LIPI dan DIKTI. Dengan berlakunya Peraturan Dirjen Dikti No.1 Tahun 2014, usulan akreditasi terbitan berkala ilmiah dalam bentuk cetak masih dapat dilakukan sampai tanggal 31 Maret 2016 (Akreditasi Periode I tahun 2016) dan masih menggunakan Pedoman Akreditasi sesuai Peraturan Dirjen Dikti Nomor 49/DIKTI/Kep/2011. Terkait dengan perbedaan acuan pedoman tersebut, narasumber juga menyampaikan dan mengarahkan perbedaan instrumen akreditasi Terbitan Berkala Ilmiah sebelum dan sesudah ditetapkannya pedoman akreditasi terbitan berkala ilmiah agar kepada para peserta workshop akselerasi Jurnal Kesehatan.

Pada materi ini, narasumber mengarahkan bahwa dalam penilaian akreditasi jurnal berkala ilmiah dilaksanakan secara online melalui sistem ARJUNA (Akreditasi Jurnal Nasional) pada laman http://arjuna.dikti.go.id. Selain itu, narasumber juga menjelaskan secara rinci terkait persyaratan apa saja yang perlu dipersiapkan dalam pengajuan akreditasi jurnal ilmiah, berupa memiliki ISSN elektronik dan atau cetak; memiliki kelembagaan penerbit yang jelas beserta alamatnya; memiliki ruang lingkup yang jelas (Scope); petunjuk dan template penulisan; terbit dalam bentuk elektronik menggunakan e-publishing system seperti Open Journal System (OJS); memiliki DOI (Digital Object Identifier); menggunakan aplikasi referensi dalam pengutipan dan pembuatan daftar pustaka seperti: Mendeley, Refwork, Zotero, Endnote dan lainnya; mencantumkan publication ethics dan minimum pengajuan 2 tahun. 


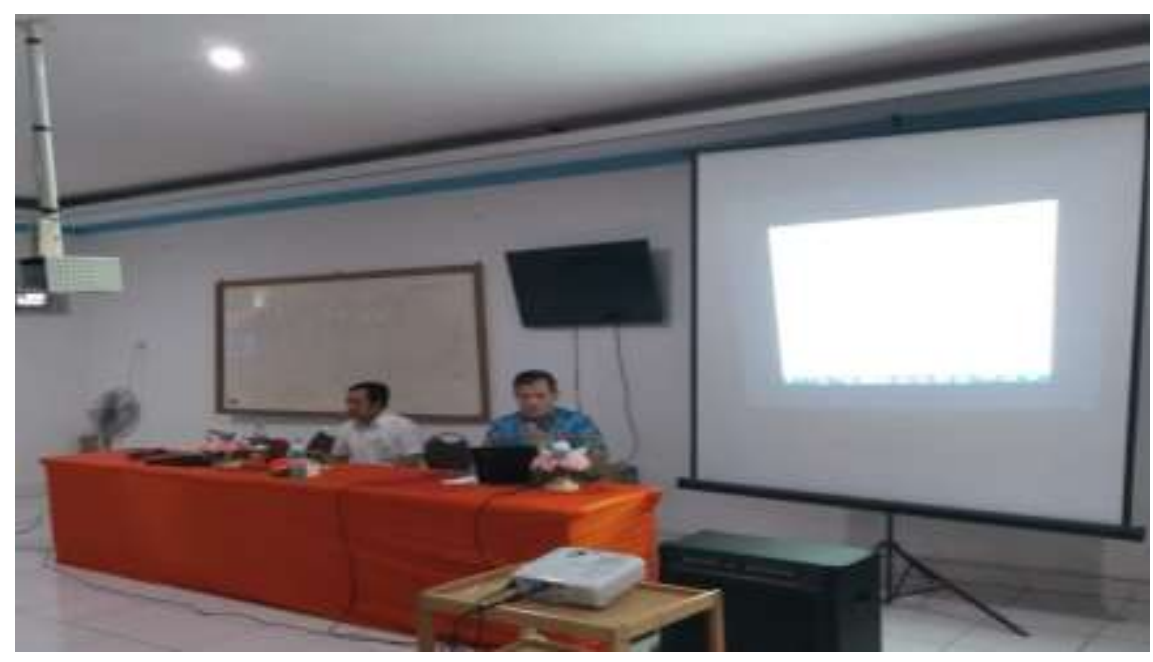

Gambar 2. Proses Penyampaian Materi oleh Narasumber

Dalam sesi ini, Tim pengelola Jurnal Kesehatan dan para Dosen di Lingkungan STIKes Cirebon sebagai peserta juga diberikan arahan terkait sistem penangkal plagiarism e-Journal. Para peserta diberikan pemahaman terlebih dahulu bahwa mengutip pernyataan tulisan orang lain tanpa mencantumkan citasi merupakan sebuah pelanggaran etika akademik yang mana akan sangat beresiko jika fenomena tersebut terjadi secara jangka panjang karena dapat berdampak terhadap pelabelan akademik yang negatif (Yandra, Zamzami, \& Febriadi, 2018). Dalam hal ini, peserta dapat menggunakan sistem aplikasi plagiat seperti Checker X sebagai sebuah sarana mengetahui persentasi originalitas artikel jurnal berkala ilmiah.

Pada penyampaian materi pemanfaatan OJS, narasumber mengawalinya dengan menyampaikan pentingnya Tim pengelola jurnal mengetahui alur proses submisi sampai publikasi karya ilmiah, memahami tentang peran dari masing-masing Tim pengelola beserta kepentingan yang saling berbeda diantara satu dengan yang lain dalam menerima informasi (Prayudi, Vijaya, \& Ekawati, 2017). Setelah itu, narasumber menyampaikan bagaimana proses penerimaan, mereview, editing sampai terbitnya artikel ilmiah sesuai dengan peran dan tugas dari masingmasing Pengelola. Tidak lupa pula dibahas mengenai informasi-informasi penting yang ada di laman publikasi ilmiah yang berbasis OJS agar dapat dipahami oleh para Dosen di Lingkungan STIKes Cirebon.

Adapun fitur-fitur tersebut sebagaimana yang dijelaskan dalam (Indriani, 2010),(Sari, 2019) diantaranya adalah :

1. Dapat diinstal, dikonfigurasikan dan digunakan secara lokal maupun berbasis web.

2. Editor dapat menggunakan perannya untuk mengkonfigurasi persyaratan, mengelola bagian, proses review, dan lain-lain.

3. Pengajuan artikel dan pengelolaan kontennya dapat dilakukan secara online (real time). 
4. Tersedia pilihan untuk menunda masa tayang setiap artikel yang diajukan.

5. Pengindeksan isi jurnal secara komprehensif menjadi bagian dari system global.

6. Editor dapat menentukan artikel mana saja yang dapat dibaca secara penuh atau hanya sebagian (abstak).

7. Setelah mengirimkan artikel, setiap penulis akan mendapatkan notifikasi melalui email yang dapat ditambahkan komentar.

8. Tersedia Online Help Support untuk setiap permasalahan yang timbul ketika sistem digunakan.

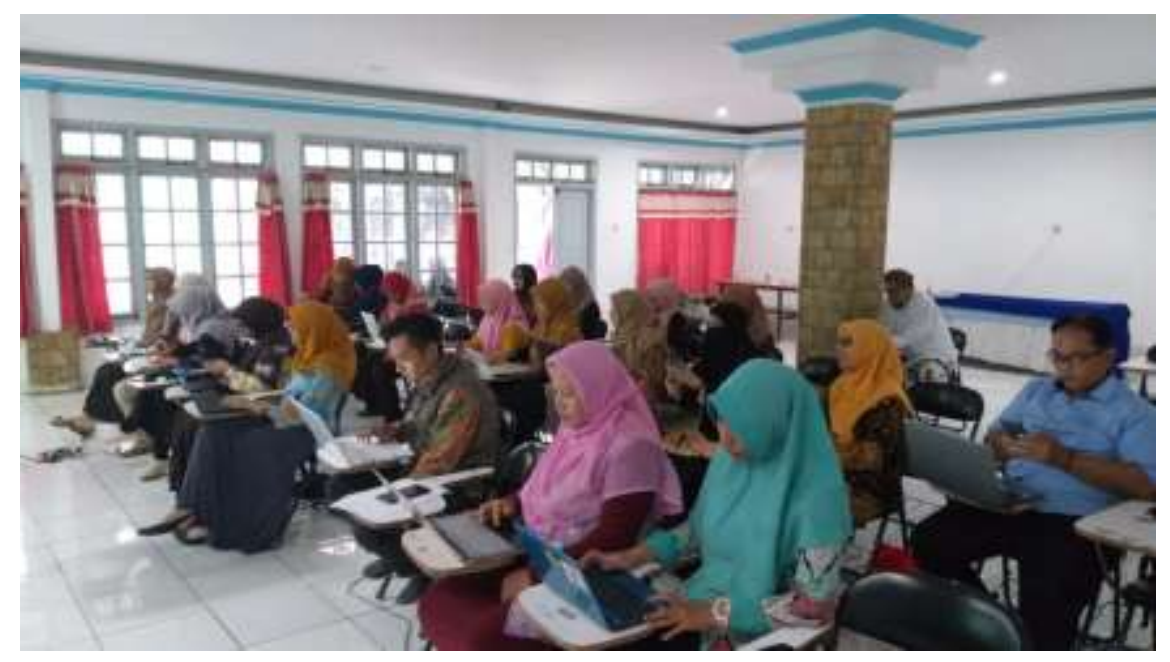

Gambar 3. Proses Penyampaian Fitur dalam OJS

Setelah itu, kegiatan workshop berlanjut dengan demontrasi pemanfaatan OJS. Narasumber memulai dengan menyampaikan cara pembuatan akun penulis melalui fitur register pada OJS sebelum dapat menjadi author pada suatu platform publikasi jurnal berkala ilmiah. Narasumber melakukan demonstrasi terkait cara melakukan registrasi bersamaan dengan dijelaskannya kolom per kolom yang perlu dilengkapi pada sistem OJS. Dalam hal ini, narasumber juga mengingatkan agar para peserta dapat melakukan ceklis pada beberapa kolom terakhir yang menegaskan tujuan dilakukannya register apakah hanya sebagai Reader, Author, atau juga sebagai Reviewer. Setelah proses demonstrasi register berjalan dengan lancar, narasumber kemudian memberikan arahan untuk proses submisi naskah pada OJS. Proses submisi naskah meliputi lima langkah, yaitu;

1. Strating the submission, melakukan submission checklist pada beberapa kolom yang telah disediakan pada OJS, setelah itu klik save and continue.

2. Upload Submission, yaitu proses mengunggah naskah artikel jurnal

3. Enter Metadata, pada tahapan ini author diminta untuk melengkapi informasi umum terkait naskah artikel yang telah di unggah pada tahapan sebelumnya, seperti judul artikel, abstrak dan kata kunci, serta daftar pustaka. 
4. Upload Supplementary Files, tahapan ini dimaksudkan untuk mengunggah lampiran pendukung penelitian seperti dokumentasi penelitian, hasil pengolahan uji statistik dan dokumen pendukung lainnya.

5. Confirmation, merupakan tahapan terakhir dalam proses subsimi artikel jurnal. Dalam tahapan ini Author hanya perlu mengkonfirmasi terkait kepastian data dan file yang diunggah adalah sudah benar. Jika sudah dapat dipastikan kebenarannya, maka Author dapat mengakhiri proses submisi artikel jurnal dengan cara klik finish submission.

Pada proses demonstrasi register dan submisi naskah artikel jurnal, semua peserta berhasil melaluinya dengan tanpa kendala.

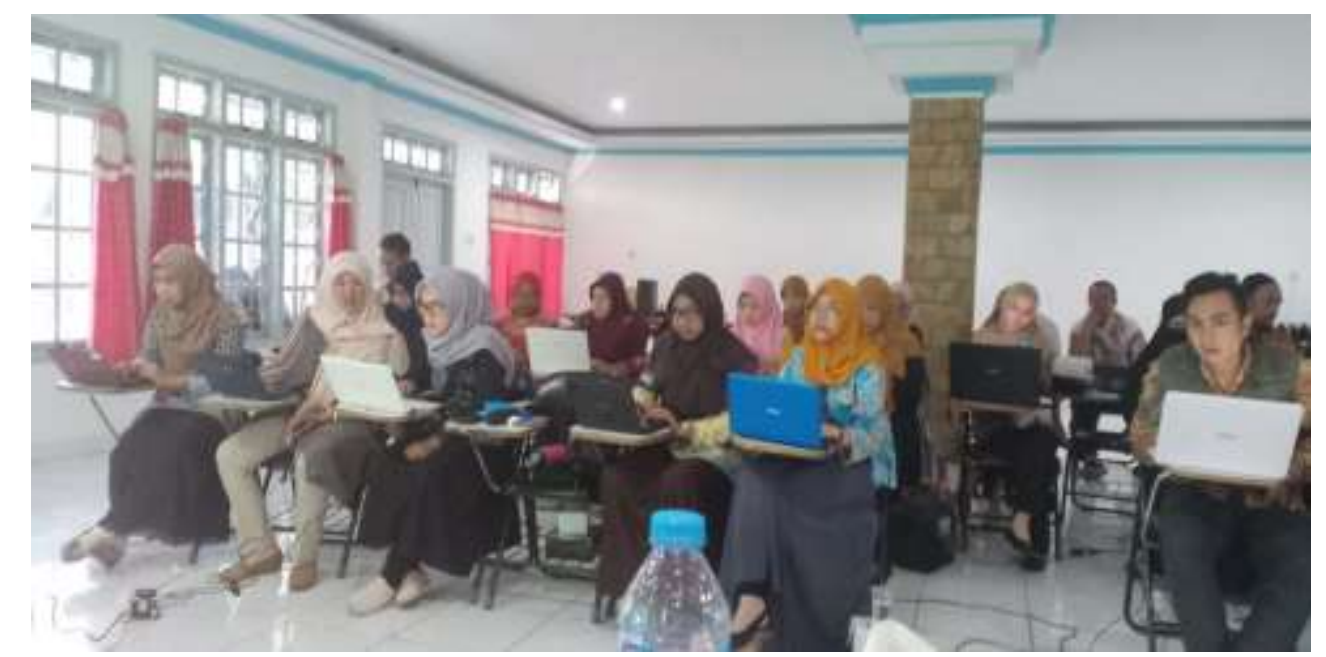

Gambar 4. Proses Praktik Pemanfaatan OJS

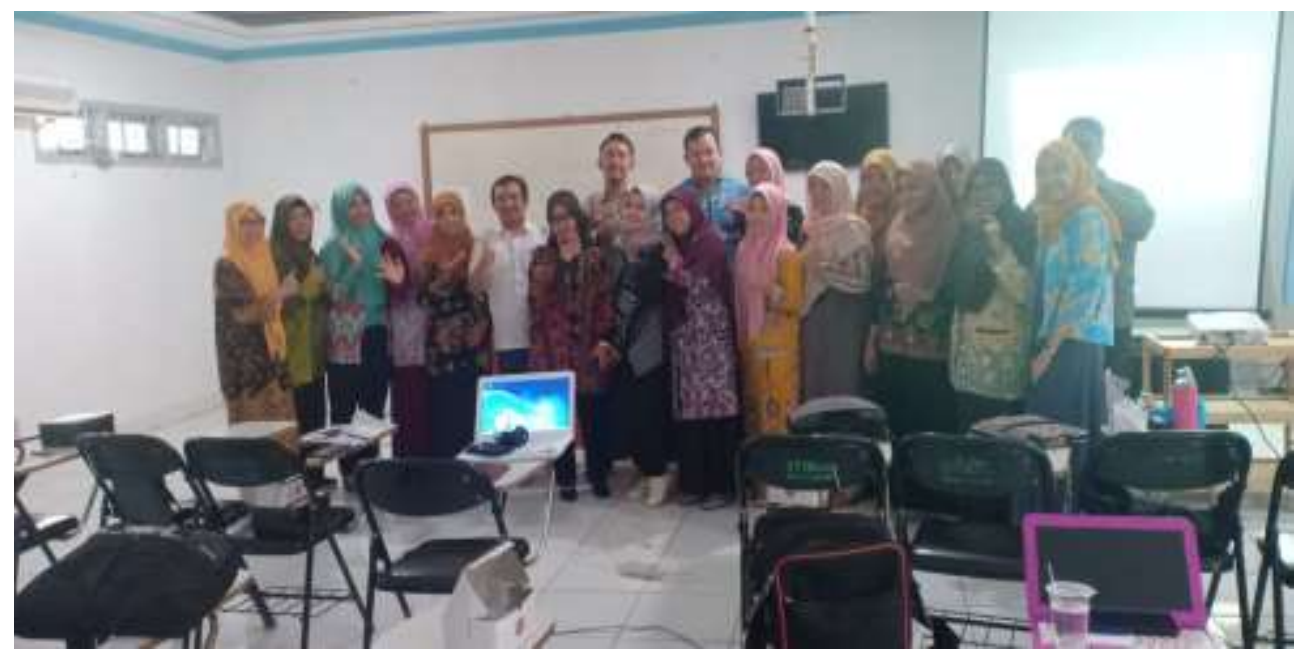

Gambar 5. Foto Bersama Narasumber dengan Peserta seusai acara Workshop

Setelah kedua sesi workshop berlangsung, narasumber menyampaikan pentingnya STIKes Cirebon belajar dari perguruan tinggi lain terutama perguruan tinggi yang berada pada satu wilayah Kota Cirebon. Dalam sesi ini, narasumber menyampaikan hasil perbandingan peringkat STIKes Cirebon dengan 10 peringkat perguruan tinggi Indonesia tertinggi dan beberapa perguruan 
tinggi di Kota Cirebon menurut Webometrics yang menyediakan list beserta pemeringkatan website perguruan tinggi dan repositori institusi (Prasetyawan, 2017). Webometrics merupakan situs yang berinisiatif untuk mempromosikan dan membuka akses publikasi ilmiah bertujuan untuk meningkatkan kehadiran akademik dan lembaga lembaga penelitian pada situs WEB yang didasarkan pada empat aspek penilaian meliputi;

1. Presence, yaitu diukur beradasarkan jumlah situs web, termasuk sub domain yang ada di suatu perguruan tinggi;

2. Impact, yaitu banyaknya jumlah backlink dari situs luar;

3. Openness, yaitu banyaknya jumlah file yang diakses dan terhubung dengan domain webiste perguruan tinggi melalui Google, Yahoo dan mesin pencari lainnya.

4. Excellence, yaitu banyaknya jumlah artikel ilmiah yang terpublikasi dan disitasi berdasarkan domain website Perguruan Tinggi asal penulis artikel. Penilaian dilakukan melalui mesin pencari Google Scholar.

Sementara itu, menurut (Achsan, 2010), kategori penilaian yang digunakan pemeringkatan Webometrics adalah;

1. Visibility, dengan bobot penilaian $50 \%$.

Visibility menempati bobot yang paling tinggi karena menyatakan kepopuleran situs website pada suatu Perguruan Tinggi yang dilihat oleh pihak lain. Penghitungan ini didasarkan pada banyaknya situs luar yang membuat tautan ke situs suatu Perguruan Tinggi (inlinks). Semakin tinggi nilai visibility-nya maka menggambarkan besarnya pengaruh web (web impact factor) yang semakin besar. Penilaian visibility dilakukan dengan mencari jumlah tautan ke situs suatu Perguruan Tinggi (inlinks) melalui Yahoo Site Explorer yang merupakan sebuah situs mesin pencari laman web dengan alamat http://www.yahoo .com.

2. Size, dengan bobot penilaian $20 \%$.

Penilaian size dihitung berdasarkan jumlah halaman situs web yang dimiliki suatu Perguruan Tinggi, nilai akan semakin tinggi jika jumlah halaman situs website pada suatu Perguruan Tinggi semakin banyak. Penghitungan jumlah halaman situs website tersebut dilakukan melalui mesin pencari Yahoo, Google, Live Search, dll.

3. Rich Files, dengan bobot penilaian $15 \%$.

Penilaian Rich Files ditentukan berdasarkan jumlah dokumen online yang ditautkan pada situs resmi suatu Perguruan Tinggi. Penghitungan dihitung sesuai jumlah dokumen berekstensi berupa doc (Microsoft Word), pdf (Adobe Acrobat), dan ppt (Microsoft PowerPoint). Penilaian Rich File ini juga dilakukan melalui mesin pencari mesin pencari Yahoo, Google, Live Search, dll. 
4. Scholar, dengan bobot penilaian $15 \%$.

Penilaian scholar bergantung pada artikel yang diterbitkan dan diindeks dalam database secara internasional serta disitasi berdasarkan domain situs website Perguruan Tinggi asal penulis artikel. Penilaian ini dilakukan melalui situs Google Scholar pada laman http://scholar.google.com.

\begin{tabular}{ccl}
\hline Peringkat Indonesia & Peringkat Dunia & \multicolumn{1}{c}{ Perguruan Tinggi } \\
1 & 768 & Universitas Indonesia \\
2 & 880 & Universitas Gadjah Mada \\
3 & 977 & Institut Teknologi Bandung \\
4 & 1.319 & Institut Teknologi Sepuluh November \\
5 & 1.334 & Universitas Sebelas Maret (UNS) Surakarta \\
6 & 1.357 & Universitas Brawijaya \\
7 & 1.715 & Universitas Airlangga \\
8 & 1.872 & Universitas Sumatera Utara \\
9 & 1.889 & Universitas Hasanuddin \\
10 & 2.036 & Universitas Diponegoro \\
231 & 9.198 & IAIN Syekh Nurjati Cirebon \\
413 & 14.046 & Universitas Muhammadiyah Cirebon \\
1.319 & 25.985 & STIKes Mahardika Cirebon \\
1.756 & 27.846 & STIKes Cirebon \\
\hline
\end{tabular}

Sumber: Webometrics, 2020

\section{Gambar 6. Peringkat Perguruan Tinggi Menurut Webometrics}

Berdasarkan data yang termuat pada gambar 6. Maka dapat diketahui posisi peringkat STIKes Cirebon yang masih sangat jauh jika dibandingkan dengan Perguruan Tinggi di Indonesia khususnya Perguruan Tinggi di Kota Cirebon. Salah satu strategi yang dapat dipersiapkan STIKes Cirebon saat ini adalah dengan membangun situs e-journal Open Access menuju OJS yang terakreditasi. (Achsan, 2010) situs e-journal yang dapat memudahkan para cendekiawan untuk mencari bahan referensi penelitian mereka dapat berkontribusi meningkatkan sitasi para penulis artikel sehingga meningkatkan pula nilai Excellence atau Scholar pada penghitungan penilaian Webometrics.

Saat ini, Jurnal Kesehatan STIKes Cirebon telah memiliki ruang publikasi Jurnal Ilmiah secara elektronik yang termuat pada laman http://jurnal.stikescirebon.ac.id/ dan telah mengajukan permohonan penerbitan e-ISSN pada Lembaga Ilmu Pengetahuan Indonesia (LIPI) dan Direktorat Jenderal Pendidikan Tinggi (DIKTI). 


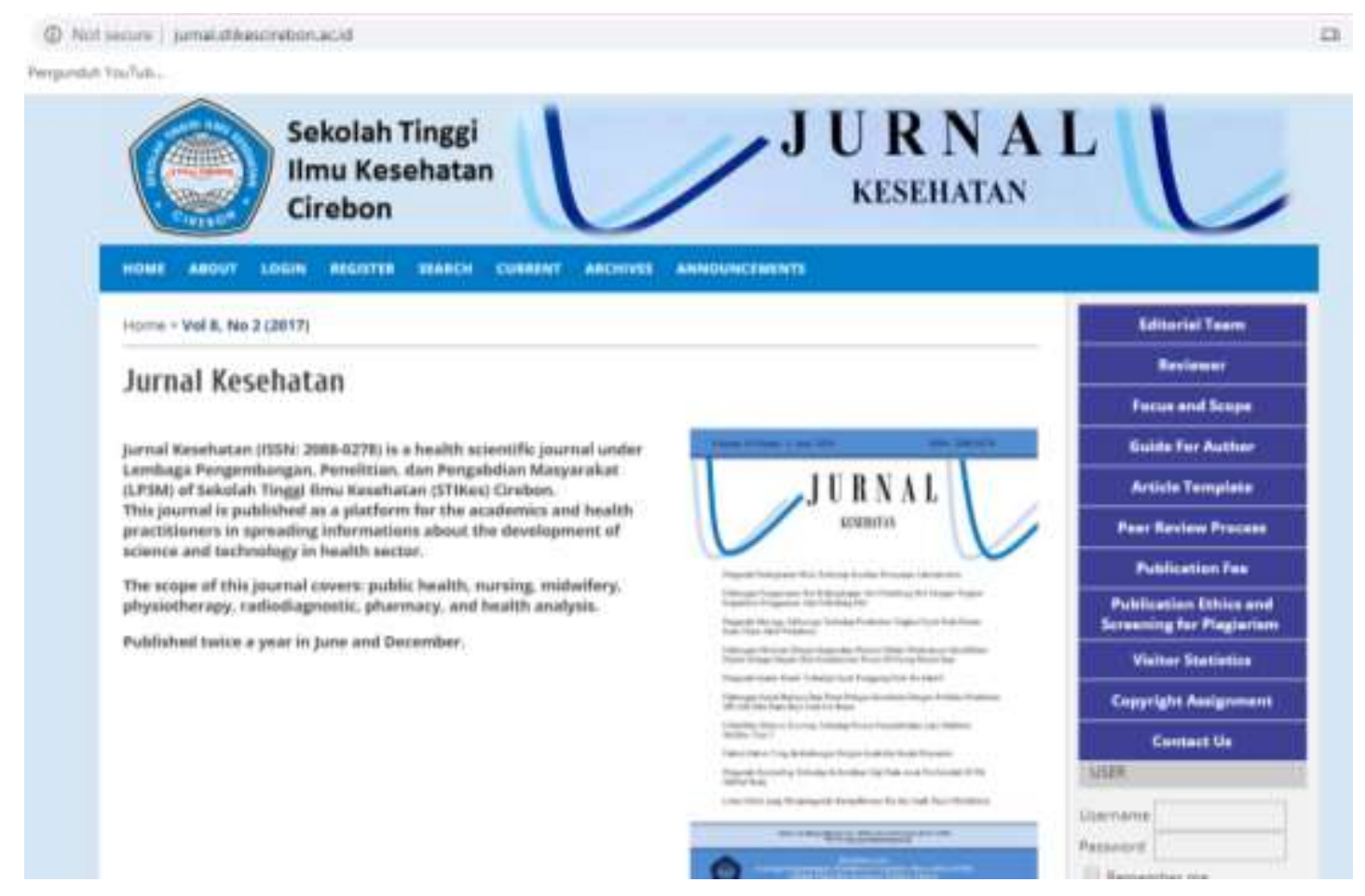

Gambar 6. Tampilan laman publikasi ilmiah Jurnal Kesehatan STIKes Cirebon

Di akhir kegiatan pendampingan, Tim pelaksana program pengabdian melakukan evaluasi bersama Tim pengelola Jurnal Kesehatan STIKes Cirebon mengenai langkah-langkah apa saja yang perlu dipersiapkan dan dilakukan agar dapat menghasilkan Jurnal elektronik/online sebagai strategi menuju jurnal yang berbasis OJS dan berakreditasi.

\section{KESIMPULAN DAN SARAN}

Kegiatan pendampingan akselerasi Jurnal Kesehatan STIKes Cirebon telah terlaksana sebagaimana yang direncanakan. Kegiatan ini dilakukan sebagai bentuk penyampaian teori serta pelatihan dan pendampingan praktik pengelolaan dari jurnal cetak menjadi jurnal elektronik/online (e-Journal) yang berbasis OJS dan terakreditasi. Berdasarkan program kegiatan pengabdian ini, bahwa masih ditemukan beberapa diantara Tim pengelola yang merasa berat memahami prosedur dan sistem pengelolaan e-Journal agar dapat terakreditasi. Sejalan dengan hal tersebut, maka kegiatan pengembangan kapasitas Dosen dan Tim pengelola STIKes Cirebon dalam hal Publikasi karya ilmiah masih perlu ditingkatkan. Hal ini tidak lain adalah untuk mengembangkan kualitas dan kuantitas hasil publikasi sekaligus meningkatkan pula mutu publikasi ilmiah pada Jurnal Kesehatan STIKes Cirebon menuju jurnal yang terakreditasi. 


\section{UCAPAN TERIMAKASIH}

Ucapan terima kasih diucapkan kepada Ketua STIKes Cirebon dan Pembantu Ketua I Bidang Akademik STIKes Cirebon yang telah banyak mendukung berjalannya program pengabdian ini.

\section{DAFTAR PUSTAKA}

Achsan, H. T. Y. (2010). Strategi Nasional menuju World Class University Versi Webometrics. Jurnal Universitas Paramadina, 7(4), 217-225.

Astuti, E., \& Isharijadi. (2019). Pengenalan Open Journal System (OJS) untuk Publikasi Ilmiah Mahasiswa. Jurnal Pengabdian Pada Masyarakat, 4(4), 409-414. https://doi.org/10.30653/002.201944.189

Aswati, S., Mulyani, N., Siagian, Y., \& Syah, A. Z. (2015). Peranan Sistem Informasi Dalam Perguruan Tinggi. Jurnal Teknologi Dan Sistem Informasi, 1(2), 79-86.

Darmalaksana, W. (2017). Analisis Kultur Penelitian dan Publikasi UIN Sunan Gunung Djati Bandung. Jurnal Informasi Riset Dan Inovasi, 1(2), 1-13.

Dewanto, Y. (2017). Peningkatan Keahlian SDM Menuju Profesionalitas Pengelolaan e-Journal. LAPAN, 4(1), 10-11.

Indriani, Y. D. (2010). Open Journal System (OJS) untuk Mengelola Publikasi Ilmiah. Jurnal Pustakawan Indonesia., 10(2).

Junandi, S. (2018). Pengelolaan Jurnal Elektronik Bidang Perpustakaan Menuju Jurnal Terakreditasi. PUSTABIBLIA; Journal of Library and Information Science, 2(1), 119-136.

Lukman. (2016). Pelatihan Penulisan Artikel Ilmiah Nasional Kementerian Riset Teknologi dan Pendidikan Tinggi; Teknologi Informasi dalam Penulisan Artikel Ilmiah. Jakarta: PDIILIPI.

Nashihuddin, W., \& Aulianto, D. R. (2017). Pengelolaan Terbitan Berkala Ilmiah Sesuai Ketentuan Akreditasi: Upaya Menuju Jurnal Terakreditasi dan Bereputasi Internasional. Jurnal Pustakawan Indonesia, 15(1-2), 83-98.

Prasetyawan, Y. Y. (2017). Perkembangan Open Access dan Kontribusinya bagi Komunikasi Ilmiah di Indonesia. Jurnal ANUVA, 1(2), 93-100.

Prayudi, M. A., Vijaya, D. P., \& Ekawati, L. P. (2017). Pengembangan Sistem Informasi Manajemen Pengelolaan dan Penerbitan Jurnal Ilmiah Jurusan Akuntansi Program S1. Seminar Nasional TEAM (Tourism, Economics, Accounting, Management): Strengthening Economic for Global Competitiveness, 2, 589-604. https://doi.org/10.23887/team.Vol2.2017.197 
Sari, D. B. K. (2019). Pengenalan Open Journal System Madika Pusat Pendidikan dan Pelatihan. MADIKA: Media Informasi Dan Komunikasi Diklat Kepustakawanan, 5(1), 95-106.

Siregar, A. R. (2008). Desain, Format dan Isi Jurnal Ilmiah. USU E-Repository, 1-7.

Yandra, A., Zamzami, Z., \& Febriadi, B. (2018). Pelatihan Penggunaan Aplikasi Pendeteksi Plagiat untuk Dosen Universitas Lancang Kuning. DINAMISIA: Jurnal Pengabdian Kepada Masyarakat, 2(2), 283-286. https://doi.org/10.31849/dinamisia.v2i2.1252

Yunus, A. M. S., Abadi, S., Bhuana, C., \& Djalal, M. R. (2018). PKM Perguruan Tinggi didalam Pembuatan dan Manajemen Open Journal System (OJS). Prosiding Seninar Hasil Pengabdian Masyarakat (SNP2M), 197-199. 